\title{
New route toward integrating large nickel nanocrystals onto mesoporous carbons
}

\author{
Ying Yang, ${ }^{\mathrm{a},{ }^{*}}$ Chengjun Sun, ${ }^{\mathrm{b}}$ Xinsong Li, ${ }^{\mathrm{a}}$ Feng Yang ${ }^{\mathrm{a}}$, Wen Zhang ${ }^{\mathrm{a}}$, \\ Xin Zhang ${ }^{\mathrm{a}, *}$ Yang Ren ${ }^{\mathrm{b}}$
}

${ }^{\text {a }}$ State Key Laboratory of Heavy Oil Processing, China University of Petroleum, Changping, Beijing 102249, China
${ }^{\mathrm{b}}$ X-ray Science Division, Argonne National Laboratory, 9700 S. Cass Ave., Argonne, Illinois 60439, USA

To whom correspondence should be addressed: Dr. Ying Yang and Prof. Dr. Xin Zhang

Postal address: No.18, Fuxue Road, Changping District, Beijing, P.R. China

Tel./fax: +86-10-89734979

E-mail address: catalyticscience@163.com and zhangxin@cup.edu.cn 


\section{ABSTRACT}

Integrating large and magnetic transition metal nanocrystals onto mesoporous carbons is of great importance owing to their low cost, easy separation and great potential in various applications. Herein we firstly report large nickel nanocrystals (Ni NCs, 30 75 nm) in situ integrated onto mesoporous carbons (MC), synthesized via block copolymer-directed self-assembly of nickel acetate and 8-quinolinol modified chitosan under neutral conditions assisted by tetraethyl orthosilicate before pyrolysis and silica removal. This neutral one-pot synthesis not only renders evenly dispersed Ni NCs firmly attached on the mesoporous carbonaceous framework without using any stabilizer, but also creates larger Ni NCs as compared to those prepared by acidic and basic synthetic routes. It is found that all nickel catalysts can be magnetically separated easily; and the Ni NC size, microstructure and the carbonaceous support morphology are well adjusted by variation of the pyrolysis temperature, which in turn affects the catalytic properties of Ni NCs towards 4-nitrophenol reduction. The Ni NC functionalized mesoporous carbon pyrolyzed at $750{ }^{\circ} \mathrm{C}$ (Ni-MC-750) simultaneously possessing twinned microstructure and carbon nanotube morphology, exhibits the highest catalytic efficiency. High-energy X-ray diffraction, $\mathrm{N}_{2}$ adsorption/desorption, transmission electron microscopy, infrared spectroscopy, X-ray absorption fine structure and Raman spectroscopy studies, as well as the comparative catalytic tests have demonstrated these points.

Keywords: Nickel nanocrystals; Mesoporous carbon; Soft-templating approach; 4-nitrophenol reduction; Magnetic separation 


\section{Introduction}

To overcome the problem pertaining to the environmental pollution, green processes have been recently achieved via chemical transformations by using green solvents, nontoxic chemicals and ambient reaction conditions. In this aspect, the disposal of nitro compounds is an area of intensive research [1-6]. Nitrophenols are among the most common organic pollutants in industrial and agricultural wastewaters. In particular, 4-nitrophenol (4-NP) is a notorious industrial pollutant exhibiting high solubility and stability in water $[7,8]$. It is therefore important to develop effective methods for its removal. There are various methods including microbial degradation, catalytic oxidation and electrochemical treatment, have been well developed for its disposal [9-11]. However, the catalytic reduction of 4-NP to 4-aminophenol (4-AP) by using sodium borohydride, which is widely used in swage treatment, is considered to be the most efficient, green and economical approach [12-15], and the reduction product namely, 4-AP, has great industrial relevance such as for aniline and paracetamol production [16]. Hence, various catalysts, including precious or doped precious metals [17-21], non-precious metals, mainly Ni-containing nanostructures [22-27], and metal-free catalysts [28], have been investigated for this process. Among which, magnetic transition metal nanocrystals (NCs) are much favored since they are low cost, and make the separation process easy by means of an external magnetic field, avoiding the conventional filtration or centrifugation procedures, which is a key obstacle preventing the industrial scale application. In spite of their significant virtues, these magnetic NCs, especially in small size, are prone to agglomeration during usage owing to their high surface energy, which will remarkably lower their catalytic activity and reduce the lifetime. Therefore, creating large NCs and dispersing them on 
porous supports are vital for construction of economical and persistent nanocatalysts for wastewater treatment.

Magnetic NCs are always immobilized on porous supports, including silica, alumina, titania, zirconia, magnesia and carbon [29-34]. Amongst them, porous carbonaceous supports are the most frequently used, and proved to be superior to oxide carriers, due to their chemical inertness and excellent stability under both acid and basic conditions. So activated carbon, because of its large specific surface area and high pore volume, is widely used as the support. However, the micropore size restricts its further application owing to the difficulty in large molecule transportation [35]. Therefore, mesoporous carbons (MC) with uniform large pores and high surface area are much in demand. Recent advances in the fabrication of NCs onto MC focus on the hard-templating approach-to infiltrate an appropriate carbon precursor (e.g. furfuryl alcohol, sucrose) and metal source (Fe, Co and Ni compounds) into the mesopores of the silica template, followed by thermal polymerization, carbonization and subsequent silica dissolution [36-39]. It is demonstrated that SBA-15 coated with 2,3-dihydroxynaphthalene (DHN) and then impregnated with nickel salt and heated, results in mesoporous carbons with evenly dispersed Ni NCs [40]. However, this multi-step synthetic procedure is time-consuming, including repeated impregnation with carbon and/or metal precursors, which may severely hamper the broad application of these composite materials. Recently, in the case of soft-templated carbons, the incorporation of inorganic species to the carbon framework can be done directly during the self-assembly process. So adding the metal salt to the reaction mixture involving the polymerizable precursors and block copolymer templates, can facilitate its transformation into metal NCs embedded in the carbon matrix during thermal treatment. This concept is well demonstrated by Zhao’s group; they use nickel 
nitrate as the metal precursor, resol as the carbon source, and Pluronic F127 as the template in the one-pot synthesis to obtain MCs with evenly distributed Ni NCs (16 $20 \mathrm{~nm}, 10 \mathrm{wt} \% \mathrm{Ni}$ ) [41]. However, more nickel precursor has to be introduced to prepare large Ni NCs, since possible Ni leaching cannot be avoided under the acidic synthetic condition. Our previous studies demonstrate that larger Ni NCs (25 40 nm) can be realized by CTAB-directed self-assembly of modified chitosan and nickel nitrate (10 wt\%) under basic conditions [42,43]. Unfortunately, the particle size cannot be further improved even increasing $\mathrm{Ni}$ percentage to $c a$. $20 \mathrm{wt} \%$. It is probable that in the presence of ammonia, the formed nickel ammine was dissolved into the reaction mixture, lowing the Ni loading. Therefore, it is speculated that under neutral synthetic conditions, much larger Ni NCs would be prepared since more $\mathrm{Ni}$ species could be captured.

We herein firstly report large nickel nanocrystals (Ni NCs, 30 75 nm, ca. 20 wt\%) in situ integrated onto mesoporous carbons (MC), synthesized via Pluronic P123-directed self-assembly of nickel acetate and 8-quinolinol modified chitoan under neutral conditions assisted by tetraethyl orthosilicate before pyrolysis and silica removal. This silica-assisted strategy strengthens the interaction between chitosan and P123 via the polymerization of chitosan with silica, rendering "homogeneous" interpenetrating silica-chitosan frameworks with evenly dispersed nickel complexes inserted, leading to homogeneously distributed $\mathrm{Ni}$ NCs on the silica-carbon frameworks in the resulting pyrolyzed samples. Silica removal created more exposed and magnetically recoverable Ni NCs, and their size, microstructure, carbonaceous support morphology, and the corresponding catalytic performances towards 4-nitrophenol reduction can be facilely tuned by variation of the pyrolysis temperature. 


\section{Experimental}

\subsection{Materials preparation}

Ni NCs were in situ integrated onto the MCs via construction of P123-directed silica-chitosan-nickel assemblings $\left(\mathrm{Ni}-\mathrm{P}_{123} \mathrm{SiC}\right)$ before pyrolysis and silica removal. First, 8-quinolinol modified chitosan, CTS-HQ, was facilely synthesized from 5-chloromethyl-8-quinolinol hydrochloride (1), involving a two-step chemical transformation from 8-quinolinol (see Supporting Information and Figs. S1-6). Then, TEOS, CTS-HQ and $\mathrm{Ni}\left(\mathrm{CH}_{3} \mathrm{COO}\right)_{2} \cdot 4 \mathrm{H}_{2} \mathrm{O}$ were respectively used as silica, carbon and metal precursors, and added stepwise to synthesize P123-directed precursor composite before pyrolysis and silica removal (Scheme 1). The molar ratio of the precursor gel in the preferred preparation is: 1 CTS-HQ: $0.5 \mathrm{Ni}\left(\mathrm{CH}_{3} \mathrm{COO}\right)_{2} \cdot 4 \mathrm{H}_{2} \mathrm{O}$ : 0.017 P123: 0.55 TEOS: $66.5 \mathrm{H}_{2} \mathrm{O}$ : $19.6 \mathrm{EtOH}$. The mixture was stirred at $40{ }^{\circ} \mathrm{C}$ for $20 \mathrm{~h}$ and then transferred into a polypropylene bottle and reacted at $100{ }^{\circ} \mathrm{C}$ under static conditions for $48 \mathrm{~h}$. The as-made product was washed, dried and pyrolyzed in a tubular furnace under $\mathrm{N}_{2}$ atmosphere. The heating rate was $2{ }^{\circ} \mathrm{C} / \mathrm{min}$ below $250{ }^{\circ} \mathrm{C}$ and $5{ }^{\circ} \mathrm{C} / \mathrm{min}$ above $250{ }^{\circ} \mathrm{C}$, and the pyrolysis was carried out at 550,750 and $950{ }^{\circ} \mathrm{C}$ for $2 \mathrm{~h}$, respectively. The resulting solid were denoted as Ni-SiMC-t, and were subjected to alkaline etching with $3.0 \mathrm{M} \mathrm{NaOH}$ solution to remove silica layers, affording Ni-MC-t, where t represents the carbonization temperature. For comparison, nickel-free mesoporous carbon (MC-750) was synthesized according to the above procedure with the maintenance of the total precursor compounds except for nickel acetate.

\subsection{Characterization}


$\mathrm{N}_{2}$ adsorption/desorption isotherms were recorded at $77 \mathrm{~K}$ with a Micromeritics Tristar II 3020. Before measurements, the samples were outgassed at $300{ }^{\circ} \mathrm{C}$ for $3 \mathrm{~h}$. The specific surface area was calculated by using the Brunauer-Emmett-Teller (BET) method and the pore size distributions were measured by using Barrett-Joyner-Halenda (BJH) analyse from the adsorption branch of the isotherms. Morphology and microstructure were analyzed using a FEI Tecnai G2 F20 TEM equipped with an energy dispersive X-ray spectroscopic analyzer operated at a voltage of $200 \mathrm{kV}$. Synchrotron X-ray diffraction measurements were performed at the 11-ID-C beamline of the Advanced Photon Source at Argonne National Laboratory. High-energy X-rays of $115 \mathrm{keV}$ energy and $0.6 \mathrm{~mm} \times 0.6 \mathrm{~mm}$ beam size were used to obtain two-dimensional (2D) diffraction patterns in the transmission geometry using a Perkin-Elmer large area detector placed at $1.6 \mathrm{~m}$ from the sample. X-ray absorption fine structure (XAFS) was carried out on a beamline at the 20-ID and 20-BM at Advanced Photo Source (APS) at Argonne National Laboratory. The XAFS data were obtained in the transmission mode at the Ni K-edge (8333.0 eV). For the Ni K-edge scan, a Ni foil was placed between the transmission and reference ion chambers. The XAFS data were processed using the Athena software for background removal, post-edge normalization, and XANES analysis. The extended X-ray absorption fine structure (EXAFS) data were analyzed using Artemis software, which implemented FEFF (Supporting Information). Raman spectra were recorded with a HORIBA Jobin Yvon HR800 with a microscope attachment. The laser wavelength of $633 \mathrm{~nm}$ was focused using a diffraction limited spot, and the scan time was $2 \mathrm{~s}$ for each sample. The infrared spectra of samples were recorded in $\mathrm{KBr}$ disks using a NICOLET impact 410 spectrometer. X-ray photoelectron spectroscopy (XPS) was performed on a Thermo ESCALAB 250Xi X-ray photoelectron spectrometer (employing a 
monochromated Al-Ka) X-ray source $(\mathrm{h} v=1486.6 \mathrm{eV})$. The C 1s line $(284.6 \mathrm{eV})$ was used as the reference to calibrate the binding energies (BE). Magnetic properties were measured by using a vibrating sample magnetometer (PTMS-VSM) with a maximum applied continuous field of $10,000 \mathrm{G}$ at room temperature.

Nickel content was estimated by inductively coupled plasma atomic emission spectroscopy (ICP-AES) analysis conducted on a Perkin Elmer emission spectrometer. Each $10 \mathrm{mg}$ sample of vacuum-dried material was placed in a digester with PTFE lined, and dissolved in $3 \mathrm{ml}$ of boiling aqua fortis solution combined with $2 \mathrm{ml}$ of $\mathrm{H}_{2} \mathrm{O}_{2}$. Microwave digestion was carried out for 30 min to completely dissolve the metal species. After cooling, each solution was filtered through a $0.45 \mu \mathrm{m}$ polyethersulfone filter and then submitted for metal analysis.

\subsection{Catalytic reduction of 4-nitrophenol}

The reduction of 4-NP was carried out in a quartz cuvette and monitored by using a UV-vis spectroscopy (754PC) at room temperature. For comparison, the yellow aqueous 4-NP solution was prepared and measured prior to monitoring the change of absorption. A total of $25 \mu \mathrm{L}$ of aqueous 4-NP solution $(0.01 \mathrm{M})$ was mixed with 2.5 mL of fresh $\mathrm{NaBH}_{4}(0.01 \mathrm{M})$ solution. Subsequently, a given amount of nickel catalyst was added to start the reaction, and the UV spectrometry was employed to monitor the reduction by measuring the absorbance of the solution at $400 \mathrm{~nm}$ as a function of time. The solution was in situ measured at certain intervals to obtain the successive information about the reaction. After the reaction was finished, the catalyst was quickly separated from the solution using a NdFeB magnet, rinsed with water and re-dispersed into the mixture of new reactants to initiate another reaction cycle. 


\section{Results and discussion}

\subsection{Understanding the synthetic strategy}

In this study, naturally-occurring macromolecule, chitosan, is chosen as the carbon precursor, and was firstly modified by 5-chloromethyl-8-quinolinol to enhance its chelation with nickel ions, interaction with surfactant P123 via hydrogen bonding, and condensation with silica in neutral aqueous phase, facilitating the formation of P123-directed silica-chitosan-nickel mesophase. This silica-chitosan-nickel mesophase provides an interpenetrating framework with a "reinforced-concrete"-like structure; both "reinforcing-steel-bar" silicate and "concrete" carbons form the mesostructured framework with evenly dispersed Ni complex inserted. Owing to the difference in chemical and thermal stability between chitosan and surfactant P123, the following pyrolysis is a unique "one stone, three birds" strategy to remove P123, carbonize CTS-HQ and reduce nickel ions by the in situ formed reducible carbon species, like CO and C, in a single step. The presence of silicates in nanocomposites dramatically inhibits framework shrinkage during the pyrolysis, and removing the silica affords replicated intercrossed carbonaceous mesostructure, during which the $\mathrm{Ni}$ NCs are further exposed.

\subsection{Sample characterization}

High-energy X-ray diffraction examination of Ni-containing samples can detect all diffractions in a short duration. As shown in Fig. 1, the precursor composite Ni- ${ }_{123} \mathrm{SiC}$ exhibits no diffractions as expected. Upon pyrolysis, all Ni-SiMC-t and Ni-MC-t samples display characteristic of fcc-structured Ni (JCPDS file 04-0805) at (111), (200), (220), (311) and (222) diffractions, indicating the formation of Ni NCs [44]. However, the diffraction intensity varies with the pyrolysis temperature. 
Samples pyrolyzed at $950{ }^{\circ} \mathrm{C}$ renders additional characteristic (100), (002) and (101) diffractions owing to rhombohedric-centered $\mathrm{Ni}_{3} \mathrm{C}$ phase [45], originating from the thermal reaction of nickel species with graphitic carbon at high temperature [46]. The small angle X-ray scattering pattern for both Ni-SiMC-750 and Ni-MC-750 shows three weak peaks at $q$ values of $0.212,0.324$ and 0.440 with a ratio of $1: 3^{1 / 2}: 2$ (Figs. S7,8), associating with 10, 11 and 20 reflections of low 2D hexagonal symmetry with p6m space group [47].

TEM images clearly show numerous spherical NCs homogeneously dispersed on the carbonaceous frameworks of Ni-MC-550, Ni-MC-750 and Ni-MC-950, and display a narrow particle size distribution with an increasing average diameter from 35.7 to $71.0 \mathrm{~nm}$ (Fig. 2), indicating the easy aggregation and growing to large particles at higher temperature. Electron microdiffraction of single $\mathrm{Ni} \mathrm{NC}$ demonstrates the $f m-3 m$ symmetrical structure (Fig. 2b,e,h); the Ni NCs in Ni-MC-550 and Ni-MC-950 are monocrystalline, while they are twinned in Ni-MC-750 [48]. Selected area electron diffraction (SAED) patterns for Ni-MC-t samples demonstrate the diffraction spots and diffraction rings assigned to crystalline Ni NCs and graphitic carbons [49], respectively. On the other hand, the morphology of carbonaceous supports changes from lapped nanoflakes, carbon nanotubes to carbon fibers when the carbonization temperature is elevated from 550,750 to $950{ }^{\circ} \mathrm{C}$, respectively, suggesting the different growth pathways.

FT-IR spectra are sensitive to the change occurred at different synthetic steps. As illustrated in Fig. 3, the precursor composite Ni-P ${ }_{123} \mathrm{SiC}$ shows C-H stretches at 2962 and $2927 \mathrm{~cm}^{-1}$ ascribed to PPO and PEO moieties from the surfactant P123, and the characteristic phenyl and pyridyl vibrations between 1760 and $1300 \mathrm{~cm}^{-1}$, as well as the silica framework vibration modes at 1098 and $465 \mathrm{~cm}^{-1}$ [50-52], confirming that 
CTS-HQ and silica have been incorporated into P123-directed silica-chitosan-nickel assemblings (Fig. 3a). However, only the characteristic silica peaks remain upon pyrolysis, indicating that P123 removal and CTS-HQ carbonization occurred (Fig. 3b). Further silica removal is supported by the disappearance of silica peaks after alkaline etching (Fig. 3c-e).

The X-ray absorption fine structure (XAFS) reveals the transition and local structure of Ni-containing species. As shown in Fig. 4, compared to Ni-P ${ }_{123} \mathrm{SiC}$, all pyrolyzed samples show the decreased white line intensity along with the newly present pre-edge peak at $c a$. $8335 \mathrm{eV}$, suggesting the $\mathrm{Ni}(\mathrm{II})$ species are mostly reduced $[53,54]$. In the corresponding $\mathrm{k}$ space, stronger oscillations at a higher $\mathrm{k}$ region of $\mathrm{k}>$ $8 \AA^{-1}$ was observed over pyrolyzed samples (Fig. S9), indicating the dominance of high Z backscatters, which would be Ni in our system. Correspondingly, the Fourier transformed EXAFS data (r space) exhibit one prominent peak at ca. $2.2 \AA$ from the Ni-Ni contributions for Ni-SiMC-t and Ni-MC-t series, different from the dominated Ni-N pairs at $c a .1 .6 \AA$ for Ni-P ${ }_{123}$ SiC. On the other hand, the Ni-Ni peak intensity, proportional to the coordination number, varies with the pyrolysis temperature and the presence of silica or not. To eliminate the systemic error, wider range (1.6 5.9 $\AA$ ) of fitting was carried out (Fig. S10), and the fitting result was shown in Table 1. For Ni-SiMC-t series, the Ni-Ni coordination number decreases from 14.1 to 5.4 as the carbonization temperature elevated from 550 to $950{ }^{\circ} \mathrm{C}$, whereas Ni-MC-t series exhibit an increase from 6.4 to 14.4. It is interesting that silica removal brings about a decrease in coordination numbers for samples pyrolyzed at 550 and $750{ }^{\circ} \mathrm{C}$, while an increase for samples pyrolyzed at $950{ }^{\circ} \mathrm{C}$. The larger coordination number than 12 may be related to the fitting error within $\pm 20 \%$. To investigate the surface properties of Ni NCs, the N1s binding energies were investigated, and the corresponding spectra 
were shown in Fig. 5. The Ni 2p $\mathrm{p}_{3 / 2}$ XPS peak at $855.4 \mathrm{eV}$ coincides with the finding for nickel oxide in Ni-SiMC-750 [55]. The CTS-HQ provides the oxygen source for the oxidation layer formation under the inert atmosphere. However, the feature extending from 855.4 to $856.0 \mathrm{eV}$ is attributed to the formation of nickel trioxide [56], suggesting more oxygen inserted during alkaline washing.

$\mathrm{N}_{2}$ adsorption reveals that all pyrolyzed samples exhibit an IV type isotherm with an $\mathrm{H}_{4}$-type hysteresis loop (Fig. 6A), characteristic of mesoporous materials bearing slit pores [57,58], with a narrow pore size distribution centered at ca. $4.3 \mathrm{~nm}$ (Fig. 6B). It is observed that the textual parameter varies with the carbonization temperature for both Ni-SiMC-t and Ni-MC-t series. As shown in Table 2, the BET surface areas decrease from $375 \mathrm{~m}^{2} \mathrm{~g}^{-1}$ for Ni-SiMC-550 to $174 \mathrm{~m}^{2} \mathrm{~g}^{-1}$ for Ni-SiMC-950, and from $317 \mathrm{~m}^{2} \mathrm{~g}^{-1}$ for Ni-MC-550 to $179 \mathrm{~m}^{2} \mathrm{~g}^{-1}$ for Ni-MC-950, respectively. More chips and larger particles produced during the framework collapse at higher temperature should be responsible for such a decrease. Different from the significantly increased surface areas and pore volumes created upon silica removal reported by $\mathrm{Hu}$ et al. [59], Ni-MC-550 and Ni-MC-750 exhibit a decline after alkaline etching, suggesting the further collapse of carbonaceous framework occurred. The local structure of carbonaceous support was investigated by Raman spectroscopy. As shown in Fig. 7, Ni-MC-t samples exhibit D and G bands centered at around 1330 and $1600 \mathrm{~cm}^{-1}$, respectively, arising from the disordered carbon and ordered graphitic sheet [60]. However, the $I_{G} / I_{D}$ (relative ratio of $G$ band to $D$ band) value decreases from 0.78 to 0.69 when the carbonization temperature was elevated from 550 to $750{ }^{\circ} \mathrm{C}$.

Magnetization curves of the nickel catalysts (Fig. 8) exhibit near-zero coercivities and remanences, suggesting a superparamagnetic nature. The corresponding saturation magnetization strength is 7.9 and $9.0 \mathrm{emu}^{-1}$ for Ni-SiMC-750 and 
Ni-MC-750, respectively, increasing with the etching of silica layer. The values are much lower than that of the bulk $\mathrm{Ni}\left(51.3 \mathrm{emu} \mathrm{g}^{-1}\right.$ ) [61], mainly due to the nanosize effect and the presence of carbon. The magnetic separability of such magnetic composites was tested in an aqueous solution by placing a magnet near the glass bottle. The powder samples can be easily attracted by the magnet and separated from the solution (Fig. 8, inset), suggesting an easy separation process.

\subsection{Catalytic properties}

The catalytic performance towards 4-NP reduction is screened in the presence of $\mathrm{NaBH}_{4}$. It is well-known that 4-NP solution exhibits a strong absorption peak at 317 nm (Fig. 9A), which is remarkably red-shifted to $400 \mathrm{~nm}$ on addition of $\mathrm{NaBH}_{4}$ due to the nitrophenolate ion formation $(\mathrm{pKa}=7.15)$ [62]. The catalytic reduction of 4-NP can be easily monitored by the reactant 4-nitrophenolate anion $\left(\lambda_{\max }=400 \mathrm{~nm}\right)$ through UV-vis spectrophotometry. A significant decrease in the absorbance at 400 nm associated with the concomitant evolution of a peak at $295 \mathrm{~nm}$ (Fig. 9B) indicates the reduction of 4-NP to 4-aminophenol (4-AP).

The catalytic efficiency of pure mesoporous carbon and Ni NC integrated mesoporous carbons towards 4-NP reduction is comparatively studied. The 4-NP conversion is calculated from $\mathrm{C}_{t} / \mathrm{C}_{0}$, measured from the relative intensity of absorbance $\left(\mathrm{A}_{t} / \mathrm{A}_{0}\right)$ at $400 \mathrm{~nm}$, where $\mathrm{C}_{0}$ and $\mathrm{C}_{t}$ are the 4-NP concentration at time $t$ and 0 , respectively. Figure 9B,C and Figs. S11-15 illustrates the absorbance vs reaction time plots towards 4-NP reduction using various catalysts. In presence of MC-750, the adsorption peak at $400 \mathrm{~nm}$ remained unaltered even for a couple of days. The reduction proceeds rapidly over Ni catalysts except for Ni-SiMC-550. Figure 9D describes the relationship between 4-NP conversion and reaction time over different 
catalysts. It is clear that the reactivity follows the sequence: Ni-MC-750 > Ni-SiMC-950 $>$ Ni-SiMC-750 > Ni-MC-950 > Ni-MC-550 > Ni-SiMC-550. To qualify the reactivity, the reaction is considered as a pseudo-first-order reaction with regard to 4-NP only to evaluate the catalytic rate, since the concentration of $\mathrm{NaBH}_{4}$ largely exceeds that of $4-\mathrm{NP}\left(\mathrm{C}_{\mathrm{NaBH} 4} / \mathrm{C}_{4-\mathrm{NP}}=100: 1\right)$. Figure $9 \mathrm{E}$ shows the liner relationship between $\ln \left(\mathrm{C}_{t} / \mathrm{C}_{0}\right)$ and reaction time, $t$, which matches the first-order reaction kinetics well, and the rate constant can be calculated from the rate equation $-\ln \left(C_{t} / C_{0}\right)=k t$. To compare different catalysts, we calculated the ratio of rate constant $\mathrm{K}$ over total weight of nickel catalyst, where $\mathrm{K}=\mathrm{k} / \mathrm{m}$. As shown in Table 2, $\mathrm{K}$ values increase over Ni-SiMC-t samples when elevating pyrolysis temperature from 550 to $950{ }^{\circ} \mathrm{C}$, linking to the more coordinatively unsaturated sites; and Ni-MC-750 shows the largest $\mathrm{K}$ value of any Ni-MC-t catalyst. On the other hand, silica removal creates more active Ni-MC-550 and Ni-MC-750 than their corresponding parent material; while less active Ni-MC-950 as compared to Ni-SiMC-950. This change rule closely relates to the change of Ni-Ni coordination number. It is clear that Ni-MC-750 shows the largest activity factor (in agreement with the comparison of TOF values listed in Table 2), which is about 2.9 times larger than the previously reported ratio for $\mathrm{NiCO}_{2}$ alloys $\left(0.95 \mathrm{~s}^{-1} \mathrm{~g}^{-1}\right)$ [23], and comparative to that for reported Ni NPs in a spherical polyelectrolyte brush nanoreactor $\left(2.4 \mathrm{~s}^{-1} \mathrm{~g}^{-1}\right)$ [17]. The largest rate constant and TOF value suggest the highest catalytic efficiency of Ni-MC-750 with defected Ni NCs anchored on carbon naonotubes with more coordinatively unsaturated sites. The best performance also can be ascribed to the rapid electron transfer rate (from $\mathrm{BH}_{4}{ }^{-}$ion to 4-NP) through graphitic carbonaceous framework [63,64], and this heterogeneous charge transfer is faster than diffusion. For this reaction, the mechanism of surface reaction was provided by Zhang et al. [65] by investigating the catalytic activity of 
Ag clusters supported on $\mathrm{TiO}_{2}$. They suggested that surface hydrogen is first transferred to the Ag nanoparticles by the decomposition of borohydride. This species then reacts with 4-NP to yield the product 4-AP. The kinetics of the reaction is modeled in terms of a Langmuir-Hinshelwood mechanism, where both reactants need to be adsorbed on the surface prior to reaction [66]. Considering the oxidation layer of nickel oxide coated on the surface of Ni NCs in this study, the proposed mechanism for the 4-NP reduction is described in Scheme 2. (i) The external nickel (tri)oxide layer was reduced by $\mathrm{NaBH}_{4}$ rapidly to give $\mathrm{Ni}(0)$ species upon mixing. (ii) Because of the chemical interaction between the particle surface and the substrates, the phenolate ions get adsorbed onto the Ni NC surface when present in the aqueous medium, forming the surface complex; Meanwhile, the strong nucleophile $\mathrm{NaBH}_{4}$, because of its diffusive nature and high electron injection capability, transfers electrons to the substrate via metal particles or carbonaceous support. This helps to overcome the kinetic barrier of the reaction. (iii) Reduction of the 4-NP by in situ produced $\mathrm{H}_{2}$ to form the adsorbed product, 4-AP, and (iv) finally desorption of the product, and the surface $\mathrm{Ni}(0)$ species was re-oxidized by ambient air to nickel (tri)oxide when $\mathrm{NaBH}_{4}$ was fully digested. The rate-determining step is governed by the reaction of the adsorbed species. The adsorption/desorption equilibrium is assumed to be much faster and is modeled in terms of a Langmuir isotherm.

To investigate the reusability, the Ni-MC-750 catalyst was facilely separated using a magnet from the catalytic reaction solution. The catalyst exhibits similar catalytic performance without visible reduction in the conversion for the same reaction time (20 min) even after running for six cycles (Fig. 9F). To further verify its stability, the Ni concentration in the reaction solution was checked by ICP-AES to be less than $0.3 \mathrm{ppm}$, indicating the negligible leaching of $\mathrm{Ni}$ into the liquid phase. Our 
TEM measurement also shows that the Ni NCs are well retained and there is no coagulation after plenty of repeating catalytic processes (Fig. S16), further suggesting the excellent stability and long life.

\section{Conclusion}

In summary, large magnetic Ni NCs (30 75 nm) have been in situ integrated onto mesoporous carbons via construction of P123-directed silica-chitosan-nickel assemblings before pyrolysis and silica removal. The soft-templated large Ni NCs were firstly realized under neutral reaction conditions, and their even dispersion on mesoporous carbons was guaranteed by controlling the metal precursor distribution in the precursor compounds. The variation of pyrolysis temperature tuned the particle size, microstructure, and the carbonaceous support morphology, as well as the

catalytic performance towards 4-NP reduction. It is demonstrated that elaborately fabricated Ni-MC-750 shows the best catalytic activity and high stability, ascribing to the combined effect of defected Ni NCs and nanotube morphology of carbonaceous framework. This work reveals new possibilities for designing and fabricating easy separated wastewater treatment catalysts by creating large metal size.

\section{Acknowledgements}

Financial support for this research work from the National Natural Science Foundation of China (21303229, 21173269, 91127040 and 51101170), and the Science Foundation of China University of Petroleum, Beijing (2462013YJRC018) is acknowledged. PNC/XSD facilities at the Advanced Photon Source, and research at these facilities, are supported by the US Department of Energy-Basic Energy Sciences, a Major Resources Support grant from NSERC, the University of Washington, the 
Canadian Light Source and the Advanced Photon Source. Use of the Advanced Photon Source, an Office of Science User Facility operated for the U.S. Department of Energy (DOE) Office of Science by Argonne National Laboratory, was supported by the U.S. DOE under Contract No. DE-AC02-06CH11357.

\section{References}

[1] J.M. Zhang, G.Z. Chen, M. Chaker, F. Rosei, D.L. Ma, Appl. Catal. B: Environ. $132(2013)$ 107-115.

[2] F. Cardenas-Lizana, D. Lamey, N. Perret, S. Gomez-Quero, L. Kiwi-Minsker, M.A. Keane, Catal. Commun. 21 (2012) 46-51.

[3] Z.Y. Zhang, C.L. Shao, P. Zou, P. Zhang, M.Y. Zhang, J.B. Mu, Z.C. Guo, X.H. Li, C.H. Wang, Y.C. Liu, Chem. Commun. 47 (2011) 3906-3908.

[4] M. Zarejousheghani, M. Moeder, H. Borsdorf, Anal. Chim. Acta 798 (2013) 48-55.

[5] X. Li, X. Wang, S. Song, D. Liu, H. Zhang, Chem. Eur. J. 18 (2012) 7601-7607.

[6] F. Coccia, L. Tonucci, D. Bosco, M. Bressan, N. d’Alessandrro, Green. Chem. 14 (2012) 1073-1078.

[7] Y.C. Chang, D.H. Chen, J. Hazard. Mater. 165 (2009) 664-669.

[8] J.-R. Chiou, B.-H. Lai, K.-C. Hsu, D.-H. Chen, J. Hazard. Mater. 248 (2013) 394-400.

[9] M.A. Oturan, J. Peiroten, P. Chartrin, A.J. Acher, Environ. Sci. Technol. 34 (2000) 3474-3479.

[10] O.A. O’Connor, L.Y. Young, Environ. Toxicol. Chem. 8 (1989) 853-862.

[11] M.S. Dieckmann, K.A. Gray, Water Res. 30 (1996) 1169-1183.

[12] Y.F. Shen, X.Y. Liu, T.H. Sun, J.P. Jia, RSC Advances 2 (2012) 8867-8882. 
[13] M. Muniz-Miranda, Appl. Catal. B: Environ. 146 (2014) 147-150.

[14] M.M. Mohamed, M.S. Al-Sharif, Appl. Catal. B: Environ. 142-143 (2013) 432-441.

[15] Y. Yang, Y. Guo, F. Liu, X. Yuan, Y. Guo, S. Zhang, W. Guo, M. Huo, Appl. Catal. B: Environ. 142-143 (2013) 828-837.

[16] S. Gazi, R. Ananthakrishnan, Appl. Catal. B: Environ. 105 (2011) 317-325.

[17] Z.M. Zhu, X.H. Guo, S. Wu, R. Zhang, J. Wang, L. Li, Ind. Eng. Chem. Res. 50 (2011) 13848-13853.

[18] X. Huang, X.P. Liao, B. Shi, Green Chem. 13 (2011) 2801-2805.

[19] Y.Y. Lin, Y. Qiao, Y.J. Wang, Y. Yan, J.B. Huang, J. Mater. Chem. 22 (2012) 18314-18320.

[20] G.H. Chang, Y.L. Luo, W.B. Lu, X.Y. Qin, A.M. Asiri, A.O. Al-Youbibc, X.P. Sun, Catal. Sci. Technol. 2 (2012) 800-806.

[21] Z.D. Pozun, S.E. Rodenbusch, E. Keller, K. Tran, W.J. Tang, K.J. Stevenson, G. Henkelman, J. Phys. Chem. C 117 (2013) 7598-7604.

[22] Z.M. Zhu, X.H. Guo, S. Wu, R. Zhang, J. Wang, L. Li, Ind. Eng. Chem. Res. 50 (2011) 13848-13853.

[23] K.-L. Wu, X.-W. Wei, X.-M. Zhou, D.-H. Wu, X.-W. Liu, Y. Ye, Q. Wang, J. Phys. Chem. C 115 (2011) 16268-16274.

[24] P. Sarmah, P. Deka, P. Bharali, Bull. Catal. Soc. India 12 (2013) 54-59.

[26] Z.F. Jiang, J.M. Xie, D.L. Jiang, J.J. Jing, H.R. Qin, CrystEngComm 14 (2012) 4601-4611.

[27] I.H.A. EI Maksod, E.Z. Hegazy, S.H. Kenawy, T.S. Saleh, Appl. Surf. Sci. 255 (2008) 3471-3479. 
[28] X.-K. Kong, Z.-Y. Sun, M. Chen, C.-L. Chen, Q.-W. Chen, Energy Environ. Sci. 6 (2013) 3260-3266.

[29] X.C. Wang, L.Q. Meng, F. Wu, Y.J. Jiang, L. Wang, X.D. Mu, Green Chem. 14 (2012) 758-765.

[30] J.F. Pang, A.Q. Wang, M.Y. Zheng, Y.H. Zhang, Y.Q. Huang, X.W. Chen, T. Zhang, Green Chem. 14 (2012) 614-617.

[31] S. Schimpf, C. Louis, P. Claus, Appl. Catal. A: Gen. 318 (2007) 45-53.

[32] A. Shrotri, A. Kanksale, J.N. Beltramini, H. Gurav, S.V. Chilukuri, Catal. Sci. Technol. 2 (2012) 1852-1858.

[33] E. van Ryneveld, A.S. Mahomed, P.S. van Heerden, M.J. Green, H.B. Friedrich, Green Chem. 13 (2011) 1819-1827.

[34] M. Banu, S. Sivasanker, T.M. Sankaranarayanan, P. Venuvanalingam, Catal. Commun. 12 (2011) 673-677.

[35] J. Lee, J. Kim, T. Hyeon, Adv. Mater. 18 (2006) 2073-2094.

[36] A.-H. Lu, W.-C. Li, A. Kiefer, W. Schmidt, E. Bill, G. Fink, F. Schüth, J. Am. Chem. Soc. 126 (2004) 8616-8617.

[37] A.-H. Lu, W. Schmidt, N. Matoussevitch, H. Bönnemann, B. Spliethoff, B. Tesche, E. Bill, W. Kiefer, F. Schüth, Angew. Chem. Int. Ed. 43 (2004) 4303-4306.

[38] S.M. Holmes, P. Foran, E.P.L. Roberts, J.M. Newton, Chem. Commun. (2005) 1912-1913.

[39] I.S. Park, M. Choi, T.W. Kim, R. Ryoo, J. Mater. Chem. 16 (2006) 3409-3416.

[40] P.F. Fulvio, C. Liang, S. Dai, M. Jaroniec, Eur. J. Inorg. Chem. (2009) 605-612.

[41] Y.P. Zhai, Y.Q. Dou, X.X. Liu, S.S. Park, C.-S. Ha, D.Y. Zhao, Carbon 49 (2011) 545-555. 
[42] Y. Yang, Y. Ren, C.J. Sun, S.J. Hao, Green Chem. 16 (2014) 2273-2280.

[43] Y. Yang, G. Gao, X. Zhang, F.W. Li, ACS Catal. 4 (2014) 1419-1425.

[44] G.Z. Chen, S. Desinan, R. Nechache, R. Rosei, F. Rosei, D.L. Ma, Chem. Commun. 47 (2011) 6308-6310.

[45] V.K. Portnoi, A.V. Leonov, S.N. Mudretsova, S.A. Fedotov, The Physics of Metals and Metallography 109 (2010) 153-161.

[46] C.-P. Luo, S.-X. Qi, N. Li, Z.-D. Lin, Acta Phys. Sinica 39 (1990) 1435-1440.

[47] Y.R. Liu, J. Mater. Sci. 44 (2009) 3600-3607.

[48] G.Z. Chen, S. Desinan, R. Rosei, F. Rosei, D.L. Ma, Chem. Eur. J. 18 (2012) 7925-7930.

[49] Z.X. Wu, Y.Y. Lv, Y.Y. Xia, P.A. Webley, D.Y. Zhao, J. Am. Chem. Soc. 134 (2012) 2236-2245.

[50] X.G. Wang, K.S.K. Lin, J.C.C. Chan, S. Cheng, J. Phys. Chem. B 109 (2005) 1763-1769.

[51] M.R. Maurya, S. Sikarwar, J. Mol. Catal. A: Chem. 263 (2007) 175-185.

[52] M.R. Maurya, A.K. Chandrakar, S. Chand, J. Mol. Catal. A: Chem. 270 (2007) 225-235.

[53] L.S. Sarma, C.-H. Chen, S.M.S. Kumar, G.-R. Wang, S.-C. Yen, D.-G. Liu, H.-S. Sheu, K.-L. Yu, M.-T. Tang, J.-F. Lee, C. Bock, K.-H. Chen, B.-J. Hwang, Langmuir 23 (2007) 5802-5809.

[54] O.M. Daniel, A. DeLaRiva, E.L. Kunkes, A.K. Datye, J.A. Dumesic, R.J. Davis, ChemCatChem 2 (2010) 1107-1114.

[55] M. Salavati-Niasari, F. Mohandes, F. Davar, M. Mazaheri, M. Monemzadeh , N. Yavarinia, Inorg. Chim. Acta 362 (2009) 3691-3697.

[56] Z.Y. Hou, O. Yokota, T. Tanaka, T. Yashima, Appl. Catal. A: Gen. 253 
(2003) 381-387.

[57] A. Corma, Chem. Rev. 97 (1997) 2373-2419.

[58] P.A. Robles-Dutenhefner, K.A.D. Rocha, E.M.B. Sousa, E.V. Gusevskaya, J. Catal. 265 (2009) 72-79.

[59] Q.Y. Hu, R. Kou, J.B. Pang, T.L. Ward, M. Cai, Z.Z. Yang, Y.F. Lu, J. Tang, Chem. Commun. (2007) 601-603.

[60] W. Chaikittisilp, M. Hu, H.J. Wang, H.-S. Huang, T. Fujita, K.C.-W. Wu, L.-C. Chen, Y. Yamauch, K. Ariga, Chem. Commun. 48 (2012) 7259-7261.

[61] P.Z. Si, Z.D. Zhang, D.Y. Geng, C.Y. You, X.G. Zhao, W.S. Zhang, Carbon 2003 (41) 247-251.

[62] Y.Y. Lin, Y. Qiao, Y.J. Wang, Y. Yan, J.B. Huang, J. Mater. Chem. 22 (2012) 18314-18320.

[63] X.L. Pan, X.H. Bao, Acc. Chem. Res. 44 (2011) 553-562.

[64] H. Wu, X. Huang, M.M. Gao, X.P. Liao, B. Shi, Green Chem. 13 (2011) 651-658.

[65] H. Zhang, X. Li, G.J. Chen, J. Mater. Chem. 19 (2009) 8223-8231.

[66] W. Xu, J.S. Kong, Y-T.E. Yeh, P. Chen, Nat. Mater. 7 (2008) 992-996. 
Table 1 Best fit parameters obtained from the analysis of the Ni K-edge EXAFS spectra

\begin{tabular}{ccccccc}
\hline Materials & First & $\mathrm{CN}^{\mathrm{a}}$ & $\mathrm{R}[\AA]^{\mathrm{b}}$ & $\sigma^{2}\left(\times 10^{-3}\right)$ & $\Delta \mathrm{E}_{0}[\mathrm{eV}]^{\mathrm{d}}$ & $\mathrm{R}$-factor \\
& Shell & & & $\left.{ }^{\circ} \AA^{2}\right]^{\mathrm{c}}$ & & \\
\hline Ni-SiMC-550 & $\mathrm{Ni}-\mathrm{Ni}$ & $14.1 \pm 1.2$ & $2.48 \pm 0.003$ & $8.66 \pm 0.52$ & $-10.701 \pm 0.863$ & 0.010 \\
Ni-SiMC-750 & $\mathrm{Ni}-\mathrm{Ni}$ & $13.2 \pm 0.7$ & $2.48 \pm 0.003$ & $7.48 \pm 0.39$ & $-9.291 \pm 0.660$ & 0.005 \\
Ni-SiMC-950 & $\mathrm{Ni}-\mathrm{Ni}$ & $5.4 \pm 1.5$ & $2.48 \pm 0.004$ & $5.69 \pm 0.69$ & $4.847 \pm 0.821$ & 0.020 \\
Ni-MC-550 & $\mathrm{Ni}-\mathrm{Ni}$ & $6.4 \pm 0.6$ & $2.48 \pm 0.003$ & $6.89 \pm 0.69$ & $-10.113 \pm 1.098$ & 0.020 \\
Ni-MC-750 & $\mathrm{Ni}-\mathrm{Ni}$ & $8.0 \pm 0.4$ & $2.49 \pm 0.003$ & $6.49 \pm 0.42$ & $-8.444 \pm 0.665$ & 0.008 \\
Ni-MC-950 & $\mathrm{Ni}-\mathrm{Ni}$ & $14.4 \pm 1.0$ & $2.48 \pm 0.008$ & $8.12 \pm 0.50$ & $-11.371 \pm 0.771$ & 0.010 \\
Ni foil & $\mathrm{Ni}-\mathrm{Ni}$ & 12.0 & 2.48 & & & \\
\hline
\end{tabular}

${ }^{\mathrm{a}} \mathrm{CN}=$ coordination number

${ }^{\mathrm{b}} \mathrm{R}=$ coordination distance

${ }^{c} \sigma^{2}=$ Debye-Waller factor

${ }^{\mathrm{d}} \Delta \mathrm{E}_{0}=$ inner potential correction 
Table 2 Textual properties, kinetic constants and turnover frequencies of various catalysts.

\begin{tabular}{|c|c|c|c|c|c|c|c|c|c|}
\hline Materials & $\begin{array}{c}\mathrm{S}_{\mathrm{BET}}^{\mathrm{a}} \\
\left(\mathrm{m}^{2} \mathrm{~g}^{-1}\right)\end{array}$ & $\begin{array}{l}\mathrm{S}_{\text {micro }} \mathrm{b} \\
\left(\mathrm{m}^{2} \mathrm{~g}^{-1}\right)\end{array}$ & $\begin{array}{c}\mathrm{V}_{\mathrm{p}} \\
\left(\mathrm{cm}^{3} \mathrm{~g}^{-1}\right)\end{array}$ & $\begin{array}{c}\mathrm{V}_{\text {micro }} \\
\left(\mathrm{cm}^{3} \mathrm{~g}^{-1}\right)\end{array}$ & $\begin{array}{l}\mathrm{D}_{\mathrm{p}}^{\mathrm{c}} \\
(\mathrm{nm})\end{array}$ & $\begin{array}{c}\mathrm{k} \times 10^{3} \\
\left(\mathrm{~s}^{-1}\right)\end{array}$ & $\begin{array}{c}\mathrm{K} \\
\left(\mathrm{s}^{-1} \mathrm{~g}^{-1}\right)\end{array}$ & $\begin{array}{c}\text { Ni loading }{ }^{\mathrm{d}} \\
(\mathrm{wt} \%)\end{array}$ & $\begin{array}{l}\mathrm{TOF}^{\mathrm{e}} \\
\times 10^{3}\end{array}$ \\
\hline & & & & & & & & & $\left(\mathrm{s}^{-1}\right)$ \\
\hline Ni-SMC-550 & 375 & 89 & 0.75 & - & 5.4 & 0.02 & 0.01 & 11.0 & 0.0009 \\
\hline Ni-SMC-750 & 264 & 153 & 0.37 & 0.06 & 4.3 & 0.57 & 0.64 & 16.8 & 0.0543 \\
\hline Ni-SMC-950 & 174 & 91 & 0.29 & 0.03 & 4.3 & 1.12 & 0.66 & 22.7 & 0.0314 \\
\hline Ni-MC-550 & 317 & 228 & 0.27 & 0.10 & 4.3 & 0.23 & 0.23 & 16.2 & 0.0200 \\
\hline Ni-MC-750 & 248 & 165 & 0.27 & 0.07 & 4.3 & 1.45 & 2.76 & 21.9 & 0.1100 \\
\hline Ni-MC-950 & 179 & 102 & 0.26 & 0.04 & 4.3 & 0.52 & 0.43 & 22.5 & 0.0160 \\
\hline
\end{tabular}

${ }^{\mathrm{a}}$ The BET surface areas are obtained from the adsorption branches in the relative pressure range of 0.05-0.20.

${ }^{\mathrm{b}}$ Microporous volumes are calculated by $t$-plot method.

${ }^{c}$ The pore size distributions are calculated from the adsorption branches by the Barret-Joyner-Halenda (BJH) method.

${ }^{\mathrm{d}}$ Estimated by ICP-AES.

${ }^{\mathrm{e}}$ TOF, $\mathrm{s}^{-1}$ : (turnover frequency) moles of 4-NP converted per mole Ni per second. 
Fig. 1

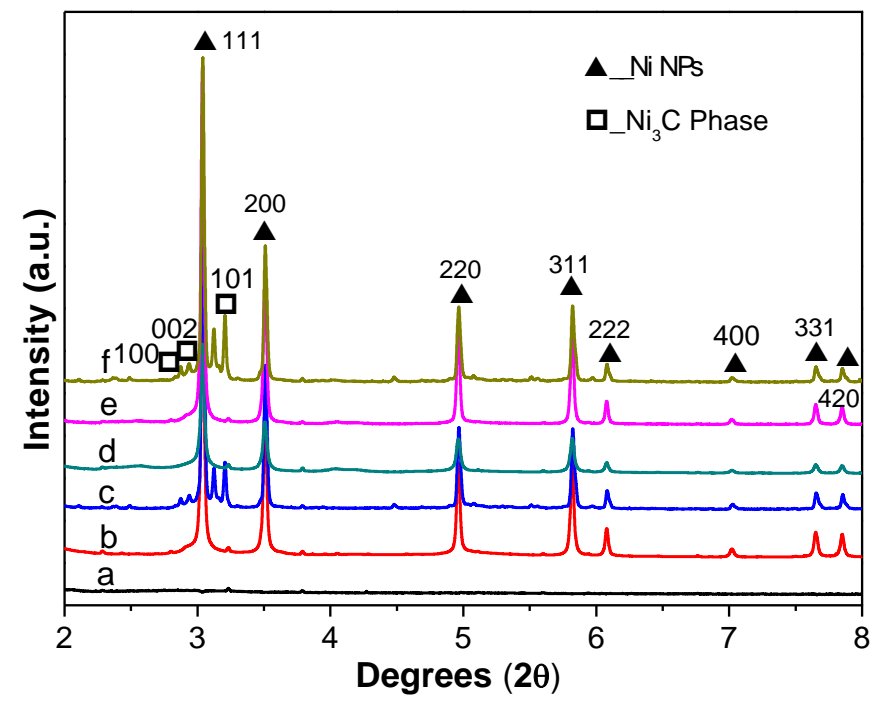

Fig. 1. High-energy $\mathrm{X}$-ray diffraction patterns of (a) Ni-P $\mathrm{P}_{123} \mathrm{SiC}$ precursor compound, (b) Ni-SiMC-750, (c) Ni-SiMC-950, (d) Ni-MC-550, (e) Ni-MC-750 and (f) Ni-MC-950. 

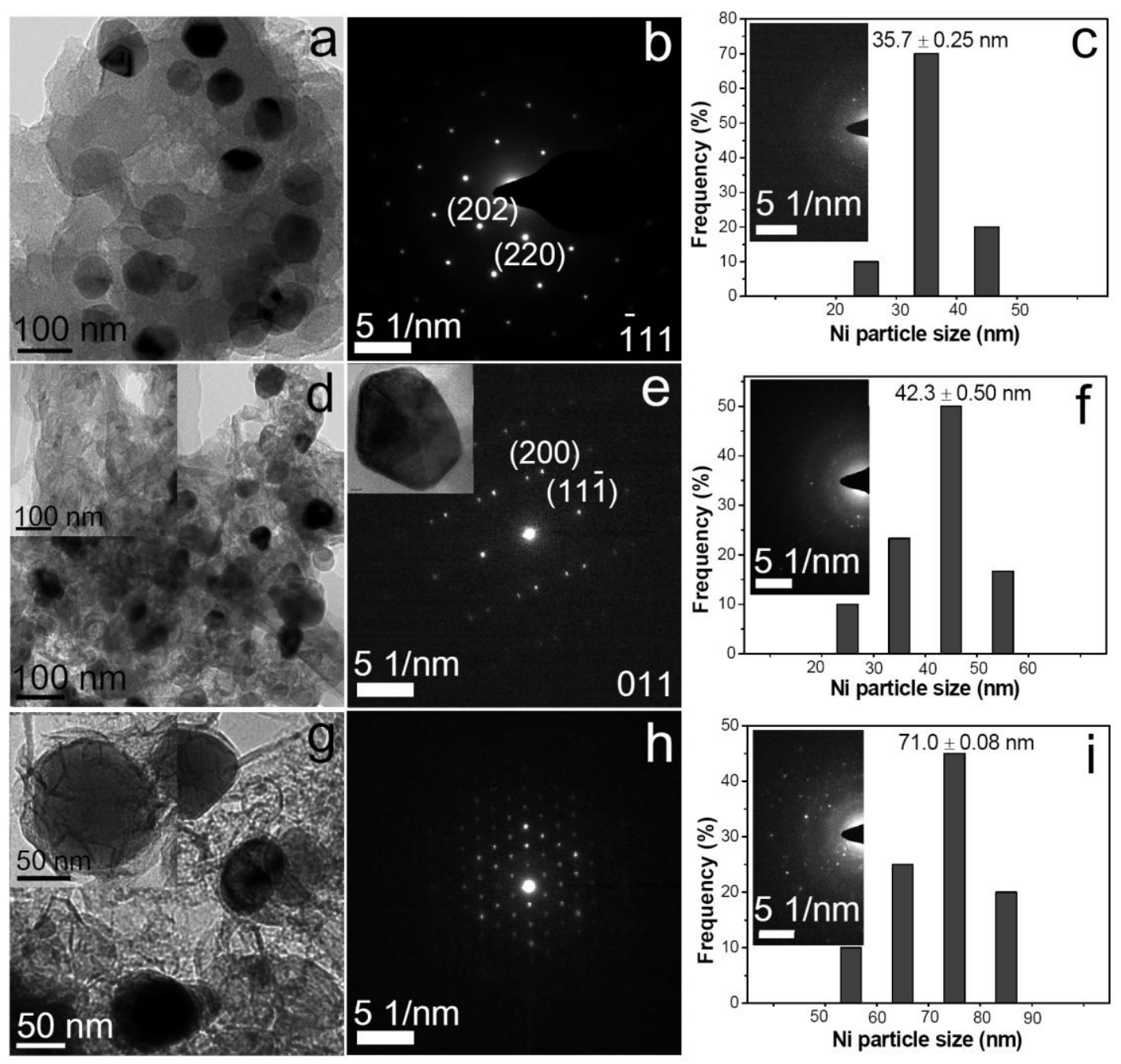

Fig. 2 TEM images, micro electron diffractions of single particle, and the particle size distributions (selected area electron diffractions, inset) for (a,b,c) Ni-MC-550, (d,e,f) Ni-MC-750 and (g,h,i) Ni-MC-950. 
Fig. 3

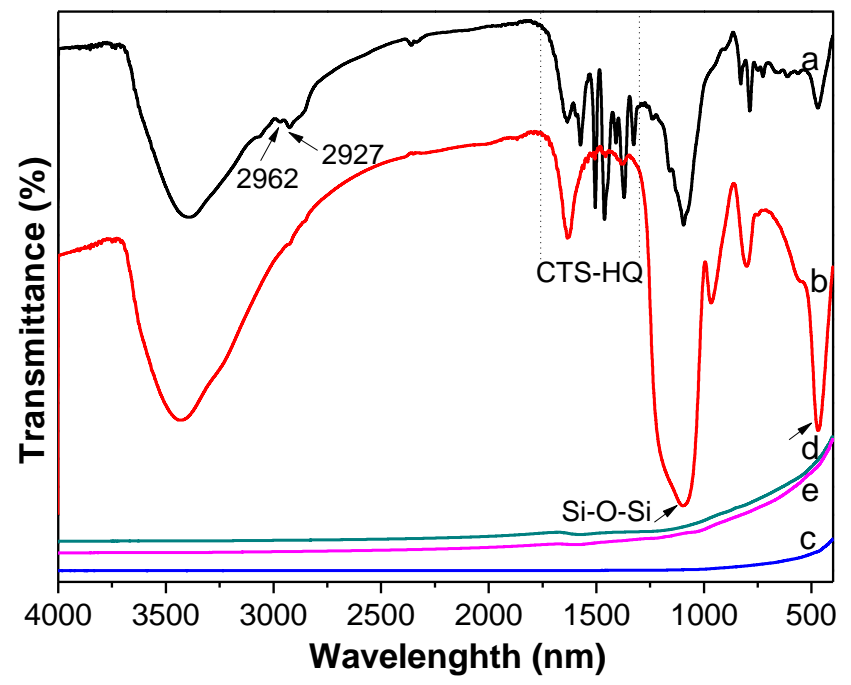

Fig. 3. FT-IR patterns of (a) Ni-P ${ }_{123} \mathrm{SiC}$, (b) Ni-SiMC-750, (c) Ni-MC-550, (d) Ni-MC-750 and (e) Ni-MC-950. 

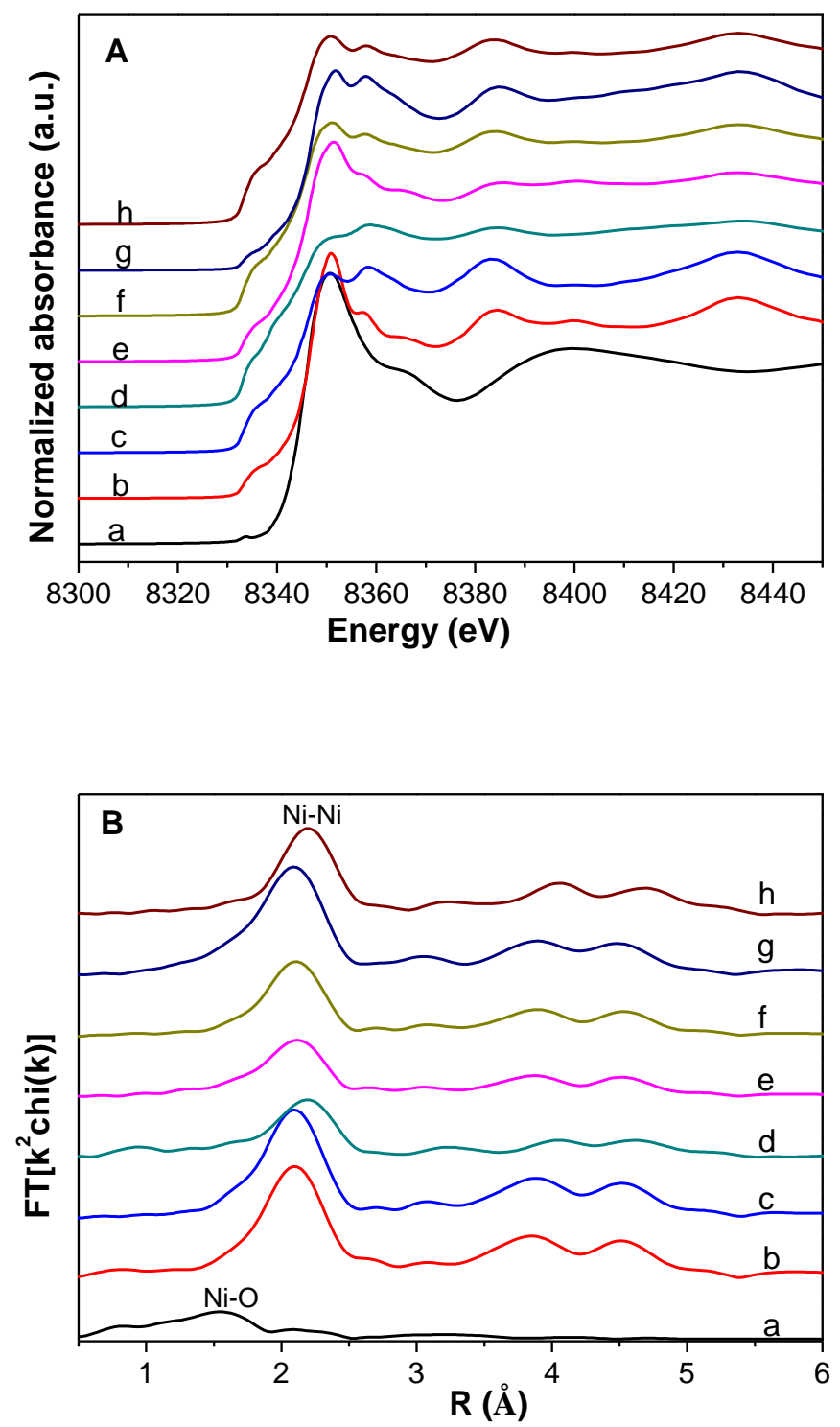

Fig. 4. (A) Ni K-edge XANES and (B) the corresponding Fourier transformed EXAFS spectra for (a) Ni-P123SiC, (b) Ni-SiMC-550, (c) Ni-SiMC-750, (d) Ni-SiMC-950, (e) Ni-MC-550, (f) Ni-MC-750, (g) Ni-MC-950 and (h) Ni foil. 
Fig. 5

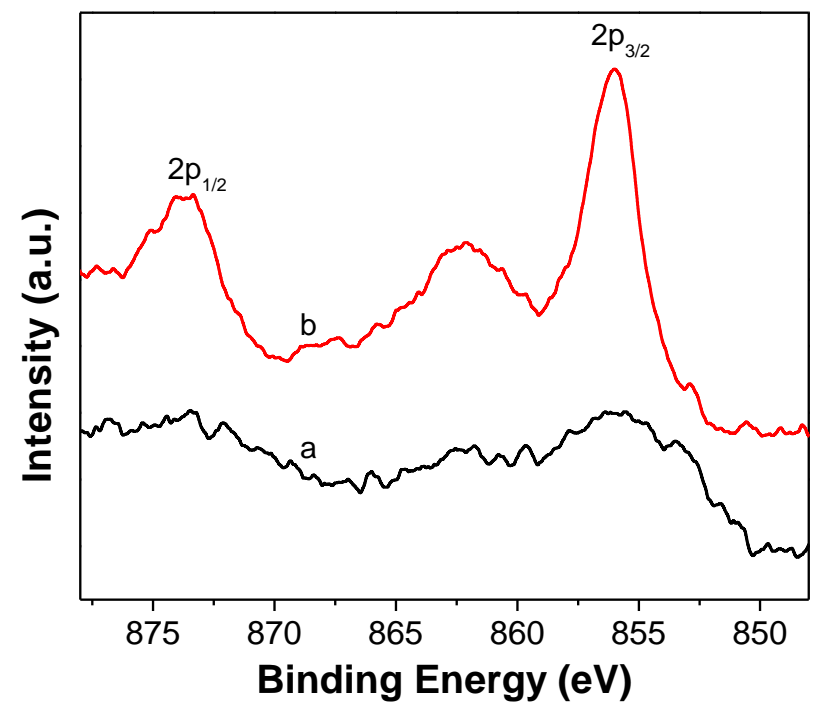

Fig. 5. XPS of Ni2p spectra for (a) Ni-SiMC-750 and (b) Ni-MC-750. 
Fig. 6
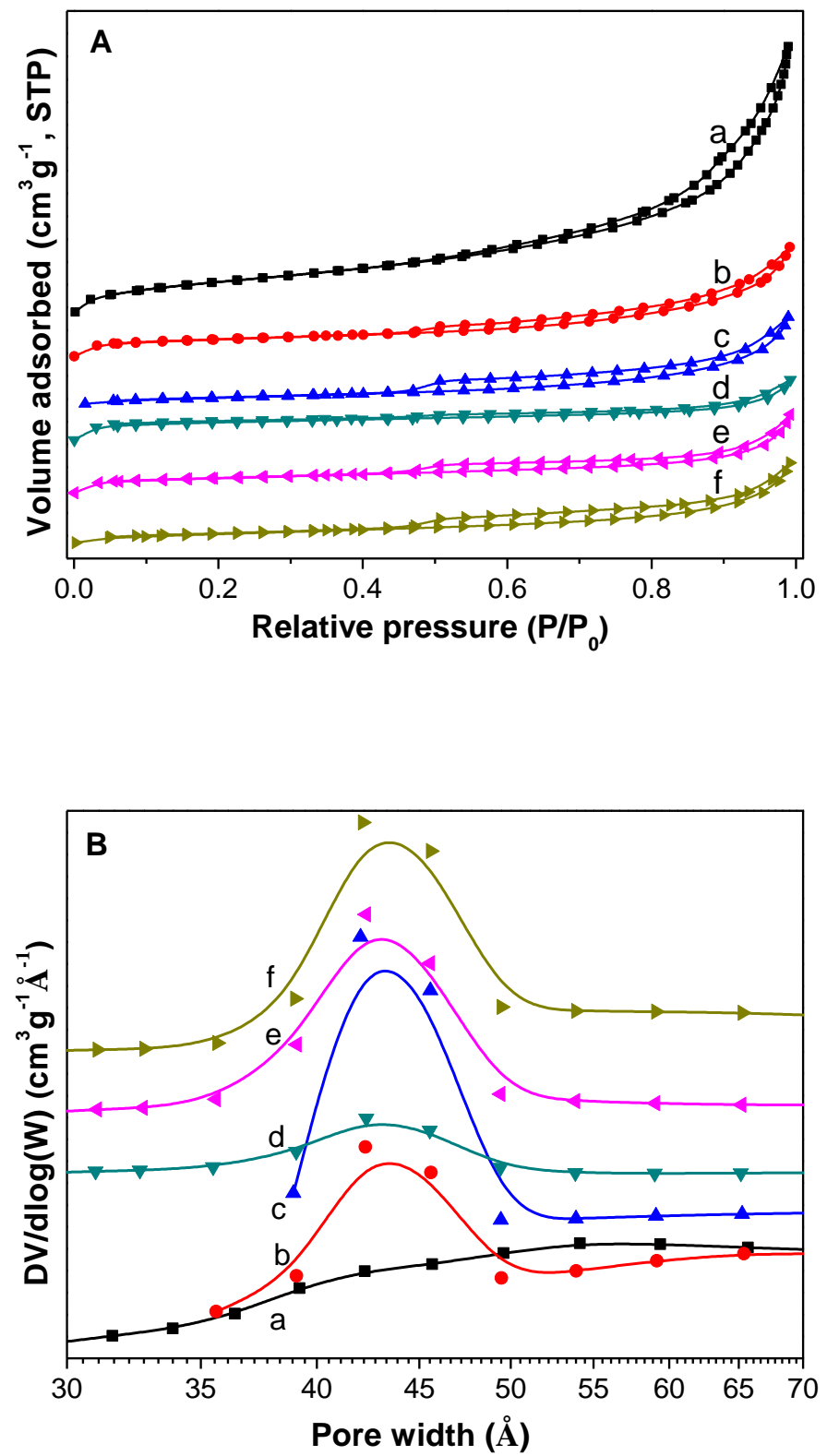

Fig. 6. (A) $\mathrm{N}_{2}$ adsorption/desorption isotherms and (B) $\mathrm{BJH}$ pore size distributions of (a) Ni-SiMC-550, (b) Ni-SiMC-750, (c) Ni-SiMC-950, (d) Ni-MC-550, (e) Ni-MC-750 and (f) Ni-MC-950. 
Fig. 7

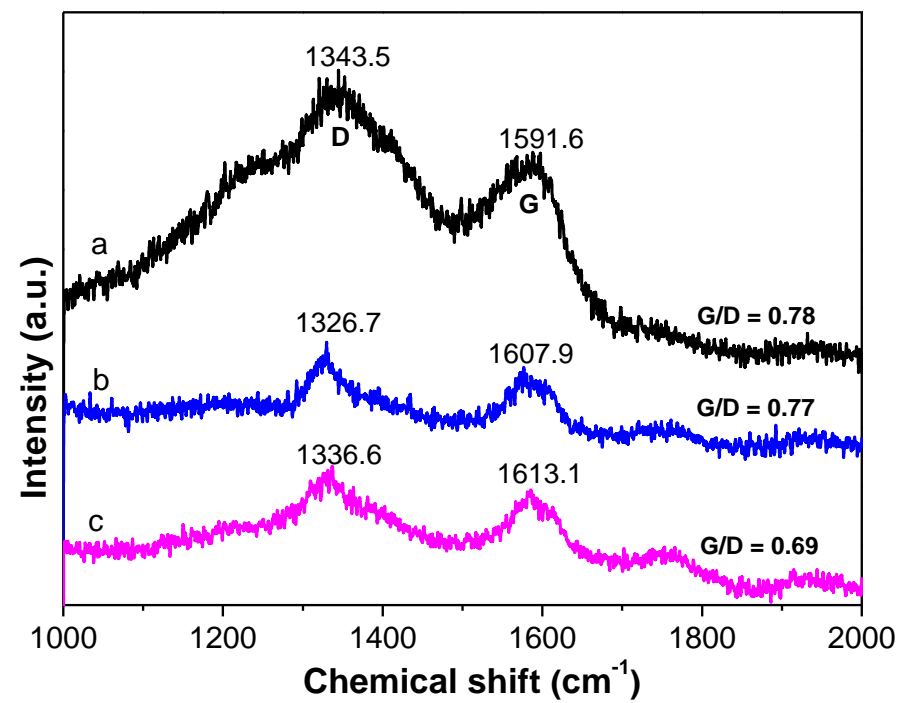

Fig. 7. Raman spectra of (a) Ni-MC-550, (b) Ni-MC-750 and (c) Ni-MC-950. 
Fig. 8

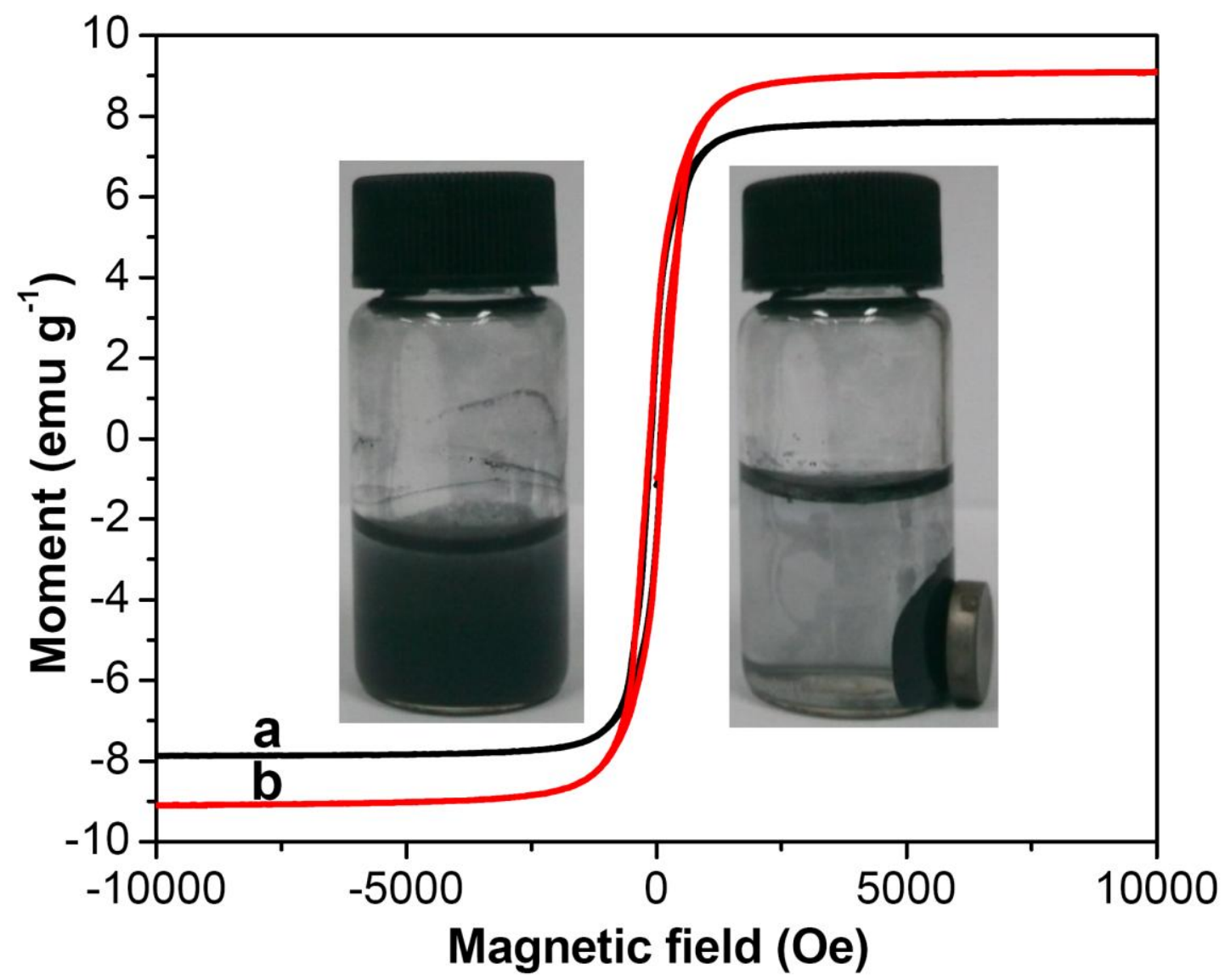

Fig. 8. Magnetization curves of (a) Ni-SiMC-750 and (b) Ni-MC-750, and the optical photo (inset) of Ni-MC-750 in an aqueous solution separated by a magnet. 

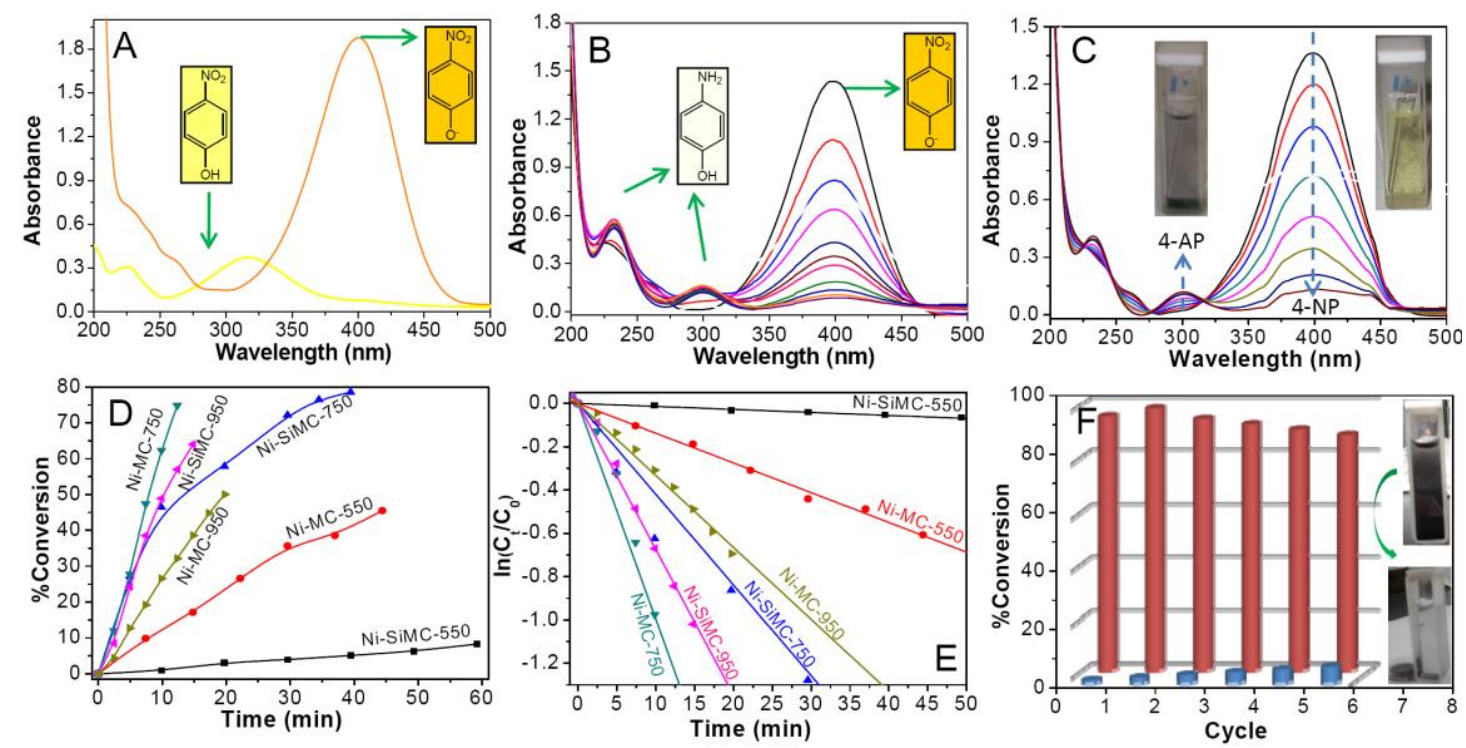

Fig. 9. (A) UV-vis spectra of 4-nitrophenol before and after adding $\mathrm{NaBH}_{4}$ solution, (B) The reduction of 4-nitrophenol in aqueous solution recorded every $4.93 \mathrm{~min}$ over 1.0 mg Ni-SiMC-750, (C) The reduction of 4-nitrophenol in aqueous solution recorded every $2.47 \mathrm{~min}$ over $0.6 \mathrm{mg}$ Ni-MC-750, (D) Time dependent conversion of 4-NP reduction catalyzed by various catalysts. (E) The relationship between $\ln \left(\mathrm{C}_{\mathrm{t}} / \mathrm{C}_{0}\right)$ and reaction time $(t)$ and (F) Catalytic conversion of 4-NP by using recycled Ni-MC-750 at different cycle times. 

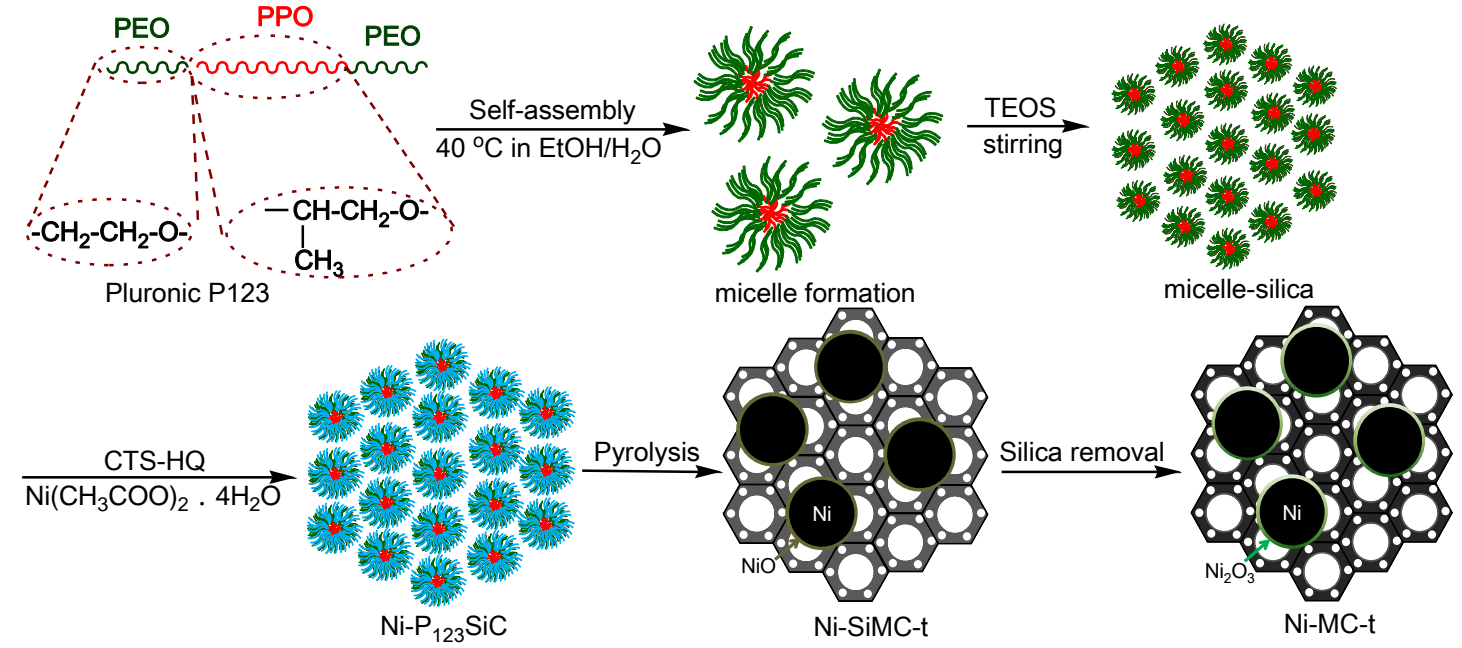

Scheme 1. Schematic description of the Ni-MC-t synthesis. 


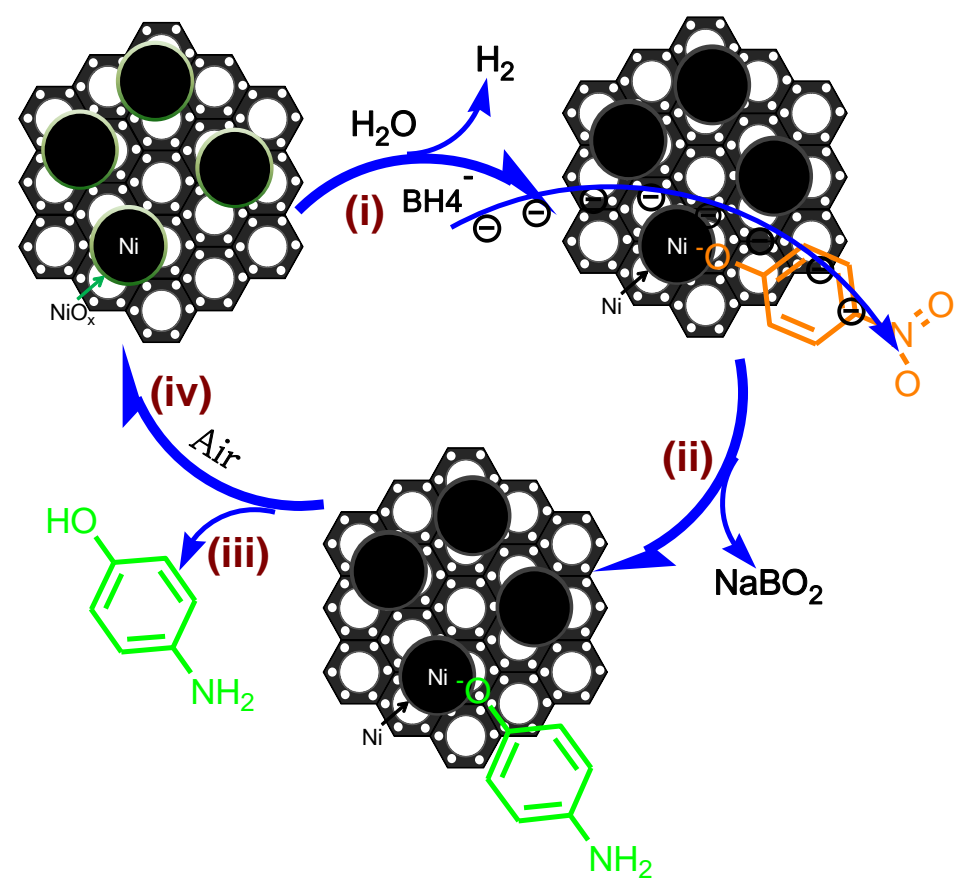

Scheme 2. Mechanistic model of Langmuir-Hinshelwood mechanism for the reduction of 4-NP to 4-AP by $\mathrm{NaBH}_{4}$ in presence of Ni NCs. 

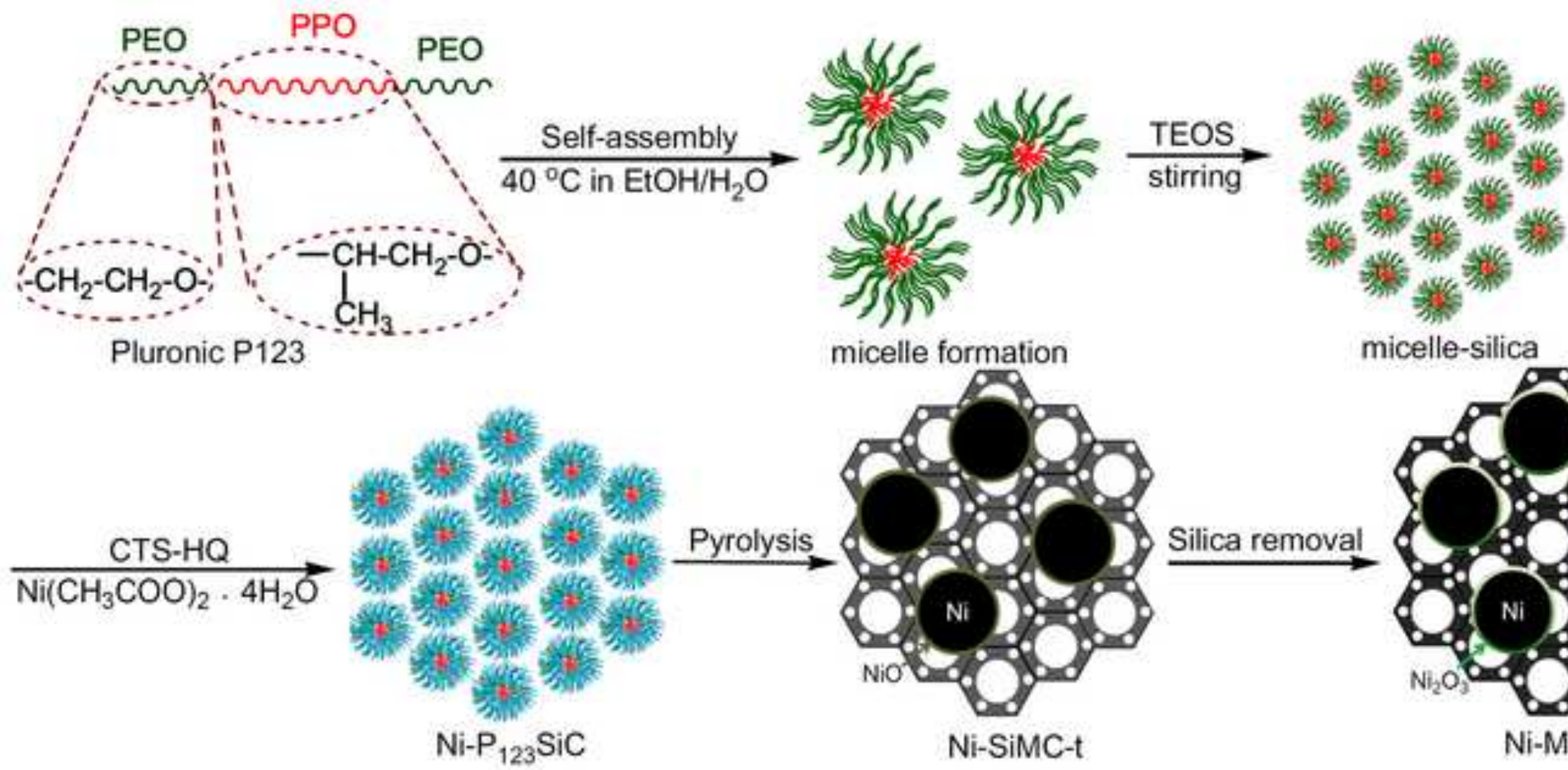

micelle formation
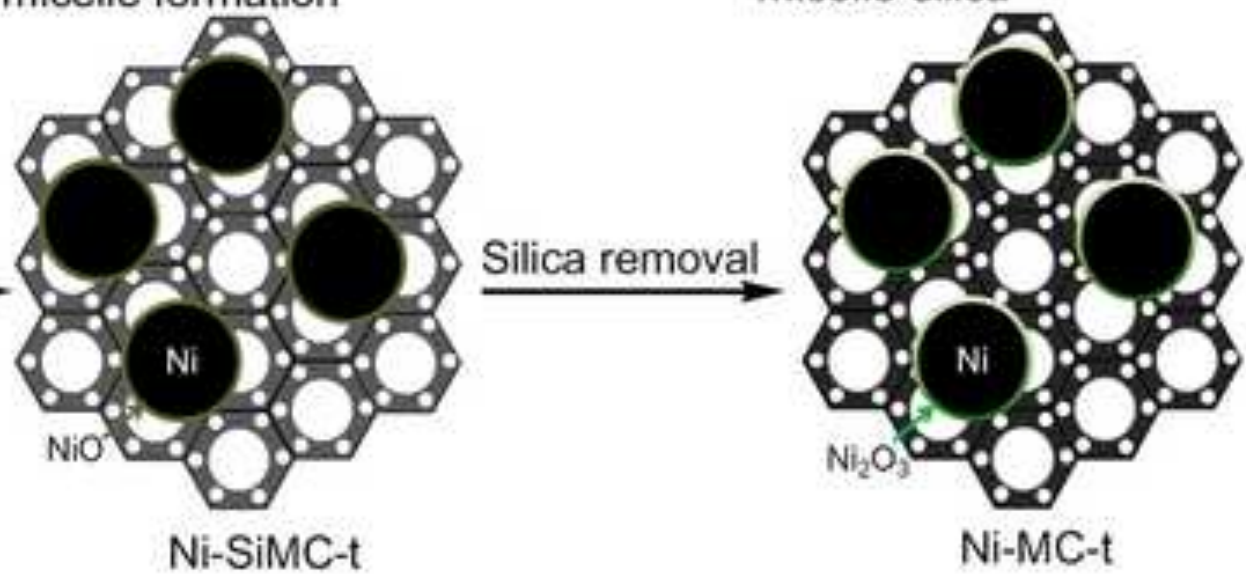

$$
\mathrm{Ni}-\mathrm{P}_{123} \mathrm{SiC}
$$

Ni-SiMC-t

Ni-MC-t 